\title{
O ENSINO DA FILOSOFIA E O PAPEL DO PROFESSOR-FILÓSOFO EM HEGEL
}

\author{
Rodrigo Pelloso GELAMO ${ }^{1}$
}

- RESUMO: Este artigo tem por objetivo trazer à luz os meandros e as particularidades do pensamento de Hegel sobre o ensino da filosofia. Embora esta não seja uma questão central em seu pensamento, é possível notar sua preocupação acerca do tema, especificamente nos textos que escreveu durante o período no qual exerceu a função de professor e diretor do ginásio em Nürember. A apresentação que aqui se faz do pensamento de Hegel sobre o ensino da filosofia divide-se em três momentos: no primeiro, são pontuados os conteúdos que ele julga necessários para a formação do pensamento filosófico; no segundo, é apresentada a questão do método e a sua relação com os conteúdos no ensino da filosofia; e finalmente, no terceiro, procura-se entender o papel que o professor exerce nesse ensino.

- PALAVRAS-CHAVE: ensino da filosofia; Hegel; filosofia alemã.

Apesar de não ter escrito nenhuma obra que tratasse essencialmente da questão educacional ou do ensino da filosofia, de forma geral, os temas desenvolvidos por Hegel tangenciam preocupações concernentes a esses dois assuntos, especialmente no que diz respeito à formação (Bildung). Hegel sempre esteve envolvido profissionalmente com o ensino. Podemos dizer que esse vínculo se inicia logo após receber o título de magister philosofiae (1790), mas é apenas em 1793 que inicia a profissão de professor, após abandonar sua formação de pastor protestante. Inicialmente Hegel foi preceptor privado (professor particular) entre 1793 e 1800 nas cidades de Berna (1793 a 1796) e Frankfurt (1797 a 1800) e, depois, de 1801 a 1806, exerceu a função de professor de filosofia da Universidade de Jena, cargo que abandonou após a guerra entre a Prússia e o exército de Napo-

1 Mestre em Filosofia e Doutorando em Educação pela Unesp, campus de Marília. Artigo recebido em 04/2008 e aprovado em 08/2008. 
leão. Os anos entre 1907 e 1908 foram os únicos nos quais Hegel ficou afastado das atividades docentes, ao aceitar a proposta de seu amigo Niethammer para ser redator do jornal Bamberger Zeitung. Logo após esse período, assumiu a função de Diretor e professor de ciências filosóficas preparatórias no Ginásio de Nuremberg. ${ }^{2}$ Em 1813, tornou-se responsável por toda a atividade docente da cidade ao tomar posse do cargo de conselheiro escolar. Neste mesmo ano deixou estas funções para se dedicar ao ensino universitário, assumindo uma cátedra na Universidade de Heidelberg e, posteriormente, em 1818 substituiu Fichte na Universidade de Berlim, onde permaneceu como professor de filosofia até sua morte, em 1831.

Durante o período em que exerceu a função de diretor em Nurenberg, Hegel escreveu alguns documentos cujos temas eram a educação, a formação (Bildung) e o ensino da filosofia. Seu pensamento sobre a educação pode ser encontrado nos seguintes textos: Discurso ao reitor Schenk (1809); Discurso de encerramento dos anos letivos, de 1809, 1810, 1811, 1813, 1815. ${ }^{3}$ Nestes discursos, Hegel dedicou-se à questão do ensino e da formação daqueles que ingressavam no Ginásio, às políticas educacionais e à organização do ensino. Notamos o interesse de Hegel pelo tema da educação em uma carta escrita a Niethammer (1821), na qual afirmava ter a intenção de escrever um livro que se dedicasse especificamente aos problemas educacionais e versasse sobre a pedagogia política. As ideias sobre o ensino da filosofia podem ser encontradas mais especificamente no informe a Niethammer de, 1812 (Acerca da exposição da filosofia nos ginásios) e no informe ao Ministério do Culto do Reino da Prússia, de 1822 (Acerca do ensino da filosofia nos ginásios). Nestes relatos, Hegel desenvolve suas ideias sobre a organização do ensino da filosofia nos Ginásios. Em um terceiro relatório enviado a Raumer, professor e conselheiro do governo prussiano (Acerca da exposição da filosofia nas Universidades), em 1816, Hegel apresenta seu pensamento sobre o lugar da filosofia, os conteúdos a serem ensinados em cada uma das etapas da formação e a maneira como a filosofia deveria ser ensinada no Ginásio e na Universidade.

Quando comparamos as ideias apresentadas por Hegel nos dois informes sobre a filosofia no Ginásio, notamos que, no primeiro informe (1812), expõe mais detalhadamente como as ciências filosóficas preparatórias precisariam se apresentar nesse momento, evidenciando os conteúdos que de-

2 Na Alemanha do período em que Hegel foi professor e diretor, o Ginásio correspondia aos quatro últimos anos que os alunos estudavam antes de entrar para a Universidade.

3 Esses documentos foram compilados sob o título de Nürnberger und Heidelberger Schriften. Utilizamos aqui a tradução espanhola desses escritos publicada sob o título Escritos pedagógicos (1991). Estes textos podem ser encontrados também traduzidos para a língua portuguesa pela Editora Colibri (1994). 
veriam ser desenvolvidos em cada um dos quatro anos relativos a este período de formação e a metodologia que deveria ser utilizada para ensiná-los. Já no segundo informe (1822), ele é um pouco mais reticente quanto ao lugar da filosofia no Ginásio. Diferentemente daquele, neste ele demonstra a importância de outros conhecimentos que poderiam contribuir para a formação. É importante notar, contudo, que as situações nas quais Hegel escreveu tais informes eram diferentes. O primeiro foi escrito como uma resposta ao Conselheiro escolar superior do Reino da Baviera, Inmanuel Niethammer, no momento em que Hegel ocupava o cargo de diretor e professor de filosofia no Ginásio. Nesta situação, ele estava convivendo com problemas bem específicos, relacionados à função do ensino da filosofia nessa etapa de formação, aos conteúdos e à metodologia para ensiná-los. Desta forma, procurando indicar as condições necessárias para a efetivação deste ensino, apresenta algumas soluções para as questões que envolviam tal momento. No segundo informe, Hegel já era professor na Universidade e, por isso, os problemas com os quais se deparava eram outros. Estes, diferentemente daqueles, eram relativos à falta de preparo no conhecimento da língua materna e da cultura geral dos alunos que iniciavam o curso universitário. Isso fez com que reavaliasse sua posição quanto ao ensino da filosofia no Ginásio, dando ênfase a uma formação mais geral, por meio do estudo dos clássicos e das línguas grega e latina.

Apesar de não evidenciá-las nesses escritos, Hegel tem dúvidas acerca da permanência do ensino da filosofia no ginásio. Isso aparece tanto no informe de 1822 como na carta escrita a Niethammer em 23 de outubro de 1812, por ocasião do envio do informe sobre o ensino da filosofia no ginásio. Nesta carta, faz a seguinte afirmação:

[...] falta ainda [no relatório de 1812], uma observação final, que eu, entretanto não acrescentei, dado que acerca deste ponto ainda estou em conflito comigo mesmo - a saber, que talvez todo o ensino da filosofia nos ginásios poderia parecer supérfluo, que o estudo dos antigos é mais adequado para a juventude ginasial e que segundo sua substância constitui a verdadeira introdução à filosofia. (Hegel, 1991, p. 181)

Outro motivo que o levou a não apresentar esses pontos de tensão no relatório foi a posição que ocupava em relação ao ensino da filosofia: como professor, não poderia posicionar-se contra sua especialidade e, especialmente, contra seu próprio posto de trabalho. Apesar disso, como pedagogo filósofo, sentia-se incitado a pensar sobre o assunto.

A apresentação que aqui fazemos do pensamento de Hegel sobre o ensino da filosofia divide-se em três momentos: no primeiro, procuramos pontuar os conteúdos que julga necessários para a formação do pensamento filosófico; no segundo, apresentamos a questão do método e a sua relação com os conteúdos no ensino da filosofia; finalmente, no terceiro momento, procuramos entender a função que o professor exerce nesse ensino. 
Hegel quer evitar que o ensino da filosofia se restrinja a um mero exercício de reflexão sobre algo. Ao contrário, postula que modos mais elevados de pensamento sejam oferecidos aos alunos, para que, assim, tenham a oportunidade de se desprender do mundo sensível e experimentar novas maneiras de pensar: a dialética e a especulativa. Com isso, a intenção de Hegel é criar um campo próprio para o ensino da filosofia como um saber que tenha um conteúdo específico, evitando, justamente, que ele seja feito de modo voluntarioso. Essa preocupação também está presente no texto de 1816 sobre o ensino da filosofia na universidade, no qual, diferentemente do texto de 1812, não aborda os conteúdos que precisam ser ensinados, concentrando sua apresentação nas condições de desenvolvimento de um pensamento filosófico no curto espaço de tempo reservado para a filosofia nessa etapa de formação (normalmente seis meses).

Hegel divide o informe Acerca da exposição da filosofia nos ginásios (1812) em dois aspectos: as matérias do ensino mesmo (temas e conteúdos) e o método. Fundamentado na Normativa, que regimentava o ensino daquele período, o ensino da filosofia nos quatro anos do ginásio era disposto em três etapas: inferior (Unterklasse), média (Mittelklasse) e superior (Oberklasse). Para a primeira, era estabelecido o conhecimento da religião, do direito e dos deveres; para a média, que durava dois anos, a cosmologia (Teologia natural em conexão com as Críticas kantianas) e a psicologia; para a etapa final, a enciclopédia filosófica.

No que se refere à primeira etapa do ensino da filosofia, Hegel diz estar de acordo com a Normativa, uma vez que "A exigência que se apresenta habitualmente a um ensino introdutório da filosofia consiste certamente em que se inicie pelo existente e que, a partir daí, se faça avançar a consciência ao mais elevado, ao pensamento" (Hegel, 1991, p. 134-135). Nesse sentido, prefere alterar a sequência dos conteúdos a serem ensinados, começando pelo direito, especialmente pela temática da liberdade, e avançando para as questões da moral até chegar aos níveis mais elevados de pensamento requeridos pela religião. Esse movimento do direito à religião possibilita ao estudante iniciar seus estudos por conceitos bastante simples e facilmente determináveis, uma vez que estes possuem certa aplicabilidade. Assim, aos poucos, os alunos podem aprender o exercício da abstração, a qual se configura como essencial para o pensamento filosófico. Para Hegel, uma ciência que contribui para esse movimento é a lógica, por apresentar um caráter abstrato e um conteúdo que se distancia da realidade imediata. Porém, a ciência da lógica não poderia ser uma disciplina inicial, porque não desperta tanto interesse nos alunos quanto aquelas que têm determinações práticas, como é o caso da liberdade. Notamos que a preocupação de Hegel não está apenas na apresentação de um conteúdo a ser ensinado, mas em sua acessibilidade. Por isso, procura encadear os assuntos de forma a aproximar os alunos do gosto pelo estudo da filosofia, sem perder o rigor filosófico no ato de ensiná-la. 
Nos dois anos da segunda etapa do ensino ginasial, são desenvolvidos os conteúdos teórico-espirituais, que compreendem o lógico, o metafísico e o psicológico. Para Hegel, o ensino deveria ser iniciado pelo conteúdo lógico, que é mais fácil do que os demais, porque possui um caráter abstrato e determinações mais simples quando comparado ao metafísico e ao psicológico. Na ciência da lógica, está implícita, ainda, uma parte dos conteúdos da cosmologia, cuja ênfase, segundo a Normativa, deveria se dar em uma parte da cosmologia antinômica kantiana. Esta corresponde à teologia natural dialética, na qual Kant desenvolve mais a lógica dialética do que a metafísica propriamente dita. Apesar de Hegel afirmar a necessidade de se conhecer a fundo o pensamento kantiano, não concorda que o ensino da lógica deva se limitar a esse autor, sendo necessário o estudo de sua lógica objetiva ${ }^{4}$ (que consiste na superação da lógica formal e da lógica kantiana), na qual procura apresentar a ciência da lógica em sua verdadeira dignidade. Restaria, assim, o conteúdo propriamente cosmológico requerido pela Normativa, o qual Hegel não considera interessante para o processo formativo, pois, "[...] o mundo, a matéria e coisas desse tipo, constituem um lastro inútil, um produto fantasioso da representação, que não possui valor algum" (Hegel, 1991, p. 136). Ao contrário, deve-se centrar a atenção na teologia natural e na teoria da religião, de Kant, uma vez que seria muito mais importante proporcionar um conhecimento acerca das provas da existência de Deus e uma familiarização com a crítica kantiana sobre esse assunto, para que se torne possível fazer uma nova crítica à crítica kantiana.

Hegel chama a atenção para o cuidado que é preciso ter com o conteúdo da psicologia nessa etapa da formação. Segundo ele, o ensino da psicologia pode ser danoso para a formação se ele for entendido em seu sentido mais trivial, conforme as formulações da psicologia empírica, encontrada na teoria da psicologia para crianças, de Campe. O mesmo ocorre com a psicologia de Carus, que Hegel avalia como carente de vida e de espírito. Ao contrário, para ele, a psicologia é uma ciência que se estabelece em dois níveis de pensamento: o concreto e o espiritual. Por este motivo, ela é mais complexa do que a lógica, a qual se estabelece em fundamentações puramente abstratas. Portanto, o ensino da lógica deveria preceder o da psicologia.

Hegel divide o ensino da psicologia em duas partes: a do espírito que se manifesta; e a do espírito em-si e para-si. Segundo ele, essa separação tem por objetivo entender de que forma

4 A obra Ciência da Lógica, de Hegel, é dividida em dois volumes: a Lógica objetiva e a Lógica subjetiva. Quando Hegel fala da lógica objetiva em Acerca do ensino da filosofia no ginásio, que foi escrito em 1812, possivelmente esteja referindo-se à primeira parte desse volume, A doutrina do ser, que foi publicada em 1812, pois, A doutrina da essência só seria publicada em 1813. Da mesma forma, o segundo volume dessa obra também foi publicado posteriormente, em 1816. 
[...] o espírito como consciência atua sobre as determinações como se fossem objetos e sua ação determinativa se converte para ele em uma relação com um objeto, mas de modo que ele como espírito somente atua sobre suas determinações e que as mudanças que se produzem nele são determinadas como suas atividades e assim são consideradas (Hegel, 1991, p. 135).

Para isso, na primeira parte, acerca de como o espírito se manifesta, Hegel apresenta os seguintes temas que poderiam ser trabalhados a partir de sua Fenomenologia do espírito (1807): a consciência, a autoconsciência e a razão. Especialmente nesta última, apresenta uma gradação entre sentimento, intuição, representação, imaginação etc., permitindo o entendimento do modo como o espírito se manifesta. Na segunda parte, Hegel tem por objetivo explicitar a relação do espírito consigo mesmo - como objeto de si mesmo e de suas determinações - o espírito em-si, e a relação do espírito com o para-si, enquanto caminho percorrido pela consciência de si até a sua efetivação.

Para o último ano do ensino da filosofia no ginásio, fica reservado o ensino da enciclopédia. O primeiro cuidado a se ter nessa etapa é com a eliminação de qualquer conteúdo que não seja estritamente filosófico, como é o caso da enciclopédia literária. Esse tema em específico, além de não contribuir em nada para a aprendizagem da filosofia, é vazio de conteúdo e, por isso, inútil para a formação dos jovens. Para esse momento, que se afigura como o ápice da formação, devem ser escolhidos conteúdos que representem a universalidade da filosofia e que correspondam aos conceitos fundamentais e aos princípios das suas ciências particulares. Para que não se amplie em demasia a quantidade de assuntos, deve-se restringir o ensino aos conteúdos das três ciências filosóficas fundamentais: a lógica, a filosofia da natureza e a filosofia do espírito.

A restrição indicada por Hegel tem por objetivo evitar que o ensino enciclopédico ocorra como um breve olhar para vários temas filosóficos. Por mais adequado que possa parecer - justamente por se tratar de temas filosóficos - isso poderia acarretar uma visão superficial sobre os temas e sobre o que é verdadeiramente a Filosofia. Por outro lado, todas as ciências consideradas filosóficas são necessariamente englobadas nessas ciências filosóficas fundamentais. Ademais, a lógica e a filosofia do espírito são desenvolvidas mais demoradamente nos três primeiros anos do ensino ginasial. Desse modo, o quarto ano pode ser dedicado ao estudo mais aprofundado da filosofia da natureza.

Hegel indica, ainda, ser desejável que se desenvolva, ao final desse período, a estética. Para ele, ao contrário da aridez do estudo da filosofia da natureza, a estética poderia proporcionar um curso instrutivo e agradável, por se constituir em um conhecimento apropriado para a juventude. Apenas 
a filosofia da história não seria estudada na visão global da filosofia no ginásio. No entanto, essa deficiência poderia ser sanada, abordando esse aspecto da filosofia no momento em que se estuda a ciência da religião, ao se ensinar a doutrina da providência. Com isso, Hegel procura evidenciar que o ensino da filosofia precisa se dar como um ensino enciclopédico em seu verdadeiro sentido: enkyklios + paidéia, ou seja, uma educação universal.

No informe de 1822, Hegel reafirma a necessidade de se ensinar os conteúdos fundamentais que havia descrito em 1812, mostrando a importância de seu aprendizado. Por outro lado, apresenta algumas preocupações acerca da inconsistência na formação das pessoas que entram na universidade, o que o faz reafirmar sua posição em relação aos conteúdos apresentados no relatório de 1812. Hegel acrescenta apenas um conteúdo nesse relatório em relação àquele: o ensino dos antigos. ${ }^{5} \mathrm{O}$ objetivo é proporcionar aos alunos o conhecimento das "grandes concepções históricas e artísticas dos indivíduos e povos, de seus feitos e destinos, assim como de suas virtudes, de seus princípios éticos e de sua religiosidade" (1991, p. 148). No entanto, esta atividade precisa ser feita com muito cuidado, pois, é necessário que se tenha a clareza de que o estudo dos antigos e da literatura clássica deve servir apenas como meio e não como finalidade do ensino da filosofia.

Como pudemos notar, Hegel pensa os conteúdos do ensino da filosofia de tal forma que todos eles se inter-relacionem intimamente, com a função de elevar o conhecimento do estudante para que este tenha condições de compreender a nova etapa do ensino, que é sempre mais complexa. Com isso, ele procura ensinar aos alunos uma filosofia plena de conteúdos filosóficos que não se separam do filosofar mesmo. Aprendendo os conteúdos da filosofia, os alunos aprendem o exercício de pensamento e, aprendendo o exercício de pensamento, aprendem os conteúdos da filosofia. Apesar de Hegel apresentar, no informe de 1812, os conteúdos da filosofia especificamente para a formação ginasial, podemos dizer que estes são os mesmos que precisam ser ensinados em qualquer etapa de formação, pois são essenciais para se aprender a filosofia, tendo por objetivo que o pensamento comum eleve-se ao pensamento filosófico.

5 Hegel tem profunda admiração pelos pensadores clássicos e considera o estudo de seus textos fundamental para a formação da juventude em geral, mesmo quando o assunto não é a filosofia. No Discurso de encerramento do ano letivo de 1809, faz a seguinte afirmação: "[...] para o estudo mais elevado a base tem que ser e permanecer, em primeiro lugar, a literatura dos Gregos e, em seguida, dos Romanos. A perfeição e a magnificência destas obras primas deve ser o banho espiritual, o batismo profano que dá à alma a primeira e indelével tonalidade e cor para o gosto pela ciência. E para esta iniciação não é suficiente uma tomada de conhecimento geral e exterior dos Antigos, mas temos de nos entregar a eles totalmente, para nos embebedarmos de seu ar, das suas representações, dos seus costumes, e mesmo, se se quiser, dos seus erros e preconceitos, e nos sentirmos em casa nesse mundo - o mais belo que existiu. [...] Penso que não afirmo demais quando digo que quem não conheceu as obras dos Antigos viveu sem conhecer a beleza" (Hegel, 1994, p. 32). 
Hegel vincula o filosofar ao seu conteúdo a fim de chamar-nos a atenção para um método de ensino da filosofia presente em seu tempo, o qual desvincula esses dois elementos que, para ele, não poderiam estar separados. Essa metodologia afirmava que, para se ensinar a filosofia, dever-se-ia ensinar a usar bem a razão. Afirmava, ainda, que os conteúdos não eram tão importantes, pois o filosofar não é relativo ao conteúdo, mas à forma de se pensá-lo. Para Hegel, esse procedimento eliminava a possibilidade de qualquer pensamento filosófico, pois valorizava apenas a formalidade do uso da razão, centrava-se no questionar ilimitado e desenvolvia uma circularidade entre o questionamento e a solução. Enfim, produzia-se uma a-sistematicidade do pensamento e um vazio de conteúdos no filosofar. Tudo isso tem como consequência o esvaziamento das mentes em um pensar despropositado que não propicia o pensar filosoficamente. Sem a construção do edifício do pensamento em bases sólidas (no sistema filosófico), só se teria um pensamento contingente e fragmentado. Para evitar essas discrepâncias na compreensão do que é a filosofia e do que se deve ensinar no ginásio e na universidade, seria necessário proporcionar um ensino pleno de conteúdos, pois "as ciências filosóficas contêm, acerca de seus objetos, os pensamentos universais, verdadeiros; eles são os resultados do trabalho dos gênios pensantes de todos os tempos" (Hegel, 1991, p. 141). Para Hegel, um filosofar que se detivesse apenas no ensino do uso da razão e que não estivesse marcado pelos conteúdos filosóficos (mesmo quando o ensino desse modo de pensamento é ministrado aos jovens do ginásio) não seria em nada útil para o processo formativo dos alunos. O ensino da filosofia que separa o conteúdo da forma de filosofar leva o aluno ao erro, por diferenciar algo que não pode ser diferenciado na filosofia: o filosofar de seu conteúdo. Ou seja, para Hegel, não se pode fazer uma separação entre o pensar filosoficamente e o pensar os conteúdos filosóficos, os quais dão condições para o filosofar: Filosofar é filosofar com conteúdos. Segundo Hegel:

Em geral se distingue um sistema filosófico com suas ciências particulares do filosofar mesmo. Segundo a obsessão moderna, especialmente da Pedagogia, não se tem de instruir tanto em relação ao conteúdo da filosofia, quanto se tem de procurar aprender a filosofar sem conteúdo; isto significa mais ou menos o seguinte: deve-se viajar e sempre viajar, sem chegar a conhecer as cidades, os rios, os países, os homens etc. (Hegel, 1991, p. 139)

Por esse motivo, é de suma importância não só que se tenha uma metodologia para ensinar os conteúdos da filosofia, mas também que se ensine o método filosófico de pensamento. Método e conteúdo complementam-se no ensino da filosofia e no próprio filosofar, ou seja, ensinar conteúdos da filosofia é ensinar a filosofar e ensinar a filosofar é ensinar a partir de um 
método filosófico. A metáfora utilizada por ele no fragmento acima esclarece melhor seu pensamento acerca do vínculo entre método e conteúdo. Para que o viajar realmente concretize-se, não basta apenas o deslocamento de um lugar para outro. Ao contrário, é necessário conhecer os lugares que se percorre, as cidades, os rios, os vilarejos, as ruas, os caminhos, enfim, as pessoas com as quais se encontra. Sem conhecer-se esses elementos (os conteúdos) que compõem o viajar, além de não se aprender o que é viajar, não se viaja verdadeiramente. Com o filosofar ocorre mesma coisa: é necessária uma imersão em cada um dos elementos fundamentais (conteúdos e método) da filosofia para que se saiba o que é filosofar e para que se aprenda a filosofar. "Assim, quando se conhece o conteúdo da filosofia, não só se aprende o filosofar, mas já se filosofa realmente" (Hegel, 1991, p. 139).

Os conteúdos e as etapas que Hegel considera fundamentais para o ensino da filosofia não podem ser diferentes no ginásio e na universidade; a diferença estaria apenas na profundidade de sua aprendizagem. Para ele, os conteúdos do ensino da filosofia são revestidos por três modos de pensamento: o abstrato, o dialético e o especulativo.

Abstrato, quando se encontra no elemento do pensamento em geral; mas quando meramente abstrato, em oposição ao dialético e ao especulativo, ele vem a constituir o chamado pensamento intelectual, que mantém firmes e chega a conhecer as determinações em suas diferenças fixas. O dialético é o movimento e a confusão daquelas determinabilidades fixas, a razão negativa. O especulativo é o racional em seu sentido positivo, o espiritual, somente ele é propriamente filosófico. (Hegel, 1991, p. 141)

Nesse sentido, é essencial que os alunos aprendam os três níveis de pensamento filosófico no ensino da filosofia. Dentre eles, apenas o especulativo pode ser considerado essencialmente filosófico, embora seja o mais difícil de ser realizado. O pensamento dialético e o abstrato afiguram-se como etapas necessárias para o aprendizado e para a formação do pensamento especulativo, por trazerem em si os conteúdos que compõem o pensamento filosófico. Por esse motivo, o ensino da filosofia deve restringir-se ao exercício desses três tipos de pensamento, respeitando uma sequência que possibilite ao aluno aprender a complexidade de cada uma dessas formas, elevando seu espírito ao pensamento filosófico.

Hegel considera que o primeiro passo para aprender o pensamento filosófico é o pensamento abstrato. No entanto, faz uma advertência em relação ao cuidado necessário ao ensiná-lo e, assim, evitar um erro muito comum: iniciar o ensino pela concretude das coisas ou pela sensibilidade (fazer a abstração do tronco da árvore para compreender o que é um círculo, por exemplo) e, apenas posteriormente, avançar para outras formas de pensamento mais abstratas. Essa via, além de não ser científica, é muito mais 
complicada quando comparada àquela que tem como ponto de partida a forma abstrata de pensamento em si mesma. Ao contrário, "é preciso que se subtraia da juventude primeiramente a visão e a audição, é preciso que se lhe desvie do representar concreto, que se retire a noite interior da alma, que aprenda a ver sobre esta base, a manter firmes e a diferenciar as determinações" (Hegel, 1991, p. 142). Desse modo, qualquer referência ou analogia a situações concretas e apelos à sensibilidade deve ser eliminada no ensino do pensar abstrato, evitando-se, assim, a dispersão e o falso entendimento do que é pensar abstratamente. O abstrato só pode ser entendido abstratamente, por isso, qualquer incursão à sensibilidade e à concretude só traria confusão nesse momento da aprendizagem. O suporte a ser utilizado para se ensinar o pensamento abstrato deve ser a ciência da lógica, por trazer um conteúdo adequado e, ao mesmo tempo, por evitar o esvaziamento do simples formalismo encontrado nas lógicas formais, que não possuem objetividade e cientificidade. Para Hegel, os elementos essenciais para esse ensino podem ser encontrados em sua Ciência da lógica (1812).

A etapa seguinte deve dar-se pelo estudo do pensamento dialético, que é mais complexo e mais árido do que o do abstrato. De acordo com Novelli,

O dialético é o segundo grau da forma e é, de acordo com a apreciação hegeliana, mais difícil e talvez também menos interessante para o aluno. Difícil porque se trata de se deparar com as posições que avaliam as determinações postas pelo abstrato. O momento dialético é o da contestação do antecedente através de novas determinações que ganham visibilidade muito mais pelo embate que promovem do que por si mesmas. Por isso, o momento dialético também pode ser visto como pouco interessante, pois não se trata de "concreção" e nem de "realização". (Novelli, 2005, p. 142)

Por isso, o ensino do pensamento abstrato deve preceder o do dialético, tendo em vista a criação de uma rotina, pois a juventude tem mais interesse pelas coisas materiais e concretas, e a filosofia procura a todo o momento distanciar-se justamente desse registro de pensamento. Poder-se-ia iniciar o estudo da dialética pelo modo como esta foi tratada pelos antigos eleatas. Porém, Hegel assume ter conseguido trazer contribuições importantes para se entender a configuração de um pensamento verdadeiramente dialético em sua Ciência da lógica. Isso porque, na referida obra, utiliza o método dialético para abordar os conteúdos da lógica, pois, cada novo conceito encadeia-se tendo como referência o movimento dialético que o precedeu, procurando evidenciar a coesão sistemática implicada nesse processo.

Apenas na terceira etapa do método, deve ser ensinado o pensamento especulativo, uma vez que, conforme já dissemos, é o mais difícil de ser aprendido pelos alunos. Não se pode confundir aqui o pensamento especulativo com especulação. Diferentemente da especulação, que é um questio- 
nar inconsequente sem o objetivo de alcançar a verdade, a finalidade do pensamento especulativo é criar condições para dar unidade ao pensamento, para que seja possível pensar conceitualmente e, assim, unificar aquilo que parece ser oposto e contraditório. Segundo Novelli,

Em Hegel, a especulação é compreendida como a síntese das determinações da reflexão e da intuição intelectual. O que Hegel pretende é a superação da dicotomia teoria-prática, análise e empiria, e isto é o que opera a especulação que reconhece tanto uma quanto a outra, e que ainda indica uma relação absoluta entre ambas. A separação entre razão e sentidos, sujeito e objeto, é fictícia e pretensiosa porque afirma o caráter absoluto de um e de outro. Isto é, para Hegel, uma inverdade, pois não há sujeito sem objeto, ou seja, a diferença é identificadora pela aproximação e pela unidade e não pela separação. Nesse sentido, a característica principal da Spekulation em Hegel é a da união de pensamentos e coisas, opostos e entendidos como distintos. (Novelli, 2005, p. 138)

Assim, com o pensamento especulativo, é possível elevar a consciência à compreensão do devir da história em seu processo dialético e conferir-lhe unidade. A forma especulativa, nesse sentido, é a superação, tanto da abstração quanto da dialética, pois unifica aquilo que ambas fragmentaram.

Como vimos, para Hegel, aprender a filosofar é aprender os conteúdos da filosofia, seus meandros e suas técnicas. Aprender a filosofar tem de ser um processo mediado pela intervenção do saber acumulado pela filosofia. Entretanto, não se faz filosofia apenas estudando sua história, ou seja, sem que se faça um exercício filosófico. Assim, não se pode separar um aspecto do outro, mesmo porque eles são inseparáveis. Podemos dizer que, para ele, o estudo da filosofia por meio do conteúdo e do método filosófico prepararia o aluno para o bem filosofar, ou seja, o filosofar só se realizaria por aqueles que se apropriassem do saber filosófico e dele fizessem uso. Portanto, conteúdo filosófico e atitude filosófica seriam sintetizados no filosofar. O ensinar a filosofar que ficasse restrito a uma atitude questionadora que Hegel chamaria de "pseudo-atitude filosófica" - não permitiria que o aprendiz superasse o devaneio intelectual de problematização e, além disso, traria como resultado desse processo de pensamento, apenas reflexões inconsistentes. Da mesma forma, o aprender a filosofia ou o filosofar não poderia estar restrito ao estudo, ainda que sistemático, da história da filosofia de maneira autodidata, uma vez que não seria capaz de fazer as devidas conexões entre os conteúdos da filosofia e o filosofar. Isso porque não se pode confundir conteúdos filosóficos com história dos conteúdos filosóficos, sobre a qual um autodidata fundamentaria seus conhecimentos. Segundo Hegel, o ensino da filosofia na prática educacional não funciona como deveria. Ele constata que 
Mediante a aprendizagem, a verdade passa a ocupar o lugar das explicações ilusórias. Só se tem a possibilidade de fazer avançar a ciência mesma e de alcançar nela uma verdadeira peculiaridade quando a cabeça está cheia de pensamentos; porém, isso não é o que ocorre nos centros públicos de ensino e de modo algum nos Ginásios, mas o estudo da filosofia tem de se dirigir essencialmente a esse objetivo, ou seja, que graças a ele se aprenda algo, se elimine a ignorância, que se preencha com pensamentos e conteúdos a mente vazia e que se desprenda daquela peculiaridade natural do pensamento, quer dizer, da contingência, da arbitrariedade e da particularidade da opinião. (Hegel, 1991, p. 141)

Nesse ponto surge uma figura central: o professor de filosofia, que é, para Hegel, o guardião da sabedoria.

O tesouro da cultura, dos conhecimentos e das verdades, no qual trabalham as épocas passadas, foi confiado ao professorado, para conservá-lo e transmiti-lo à posteridade. O professor tem de se considerar como o guarda e o sacerdote dessa luz sagrada, para que ela não se apague e a humanidade não recaia na noite da antiga barbárie. Essa transmissão tem de suceder por um lado, por meio de um esforço fiel, mas, simultaneamente, a letra só será verdadeiramente frutuosa pela interpretação e espírito do próprio professor. (Hegel, 1994, p. 23)

Cabe ao professor ser o anunciador e o transmissor dos saberes produzidos anteriormente pela humanidade e pela filosofia. Nesse sentido, existe uma impossibilidade de que o indivíduo aprenda sozinho a filosofia e tais saberes. O professor-filósofo é, então, essencial no ensino da filosofia porque já superou a dicotomia entre o conteúdo e o método, entre a teoria e a prática, sendo capaz, portanto, de fazer as mediações imprescindíveis para o aprendizado dos iniciantes. Hegel compreende que "O modo de proceder para familiarizar-se com uma filosofia plena de conteúdo não é outro senão a aprendizagem. A filosofia deve ser ensinada e aprendida na mesma medida em que o é qualquer outra ciência" (1991, p. 140). O professor tem papel fundamental nesse processo, pois ele é o mediador da aprendizagem. Porém,

[...] o estudo da filosofia é um trabalho próprio, já é uma aprendizagem - a aprendizagem de uma ciência configurada, já existente. Esta constitui um tesouro que consta de um conteúdo adquirido, disposto, formado; este bem herdado existente deve ser adquirido pelo indivíduo, quer dizer, deve ser aprendido. O professor o possui; ele o pensa previamente, os alunos o pensam depois. (Hegel, 1991, p. 141)

A figura do mestre é central para exercer a mediação entre o saber já instituído e aquele que está sendo construído pelo aluno. Assim, ensinar e aprender sempre são atividades mediadas pelo professor, porque não poderiam se dar de forma espontânea ou natural. O homem não teria a predisposição natural ou seria capaz de um autodidatismo. O mestre está além de 
alguém que apenas explica ou encurta caminhos para seus alunos, ele precisa ser um paradigma do filosofar por já ter uma vivencia nessa atividade. Novelli bem sintetizou o pensamento de Hegel a esse respeito:

Aprender é aprender com alguém, por intermédio de alguém, isto é, por um processo necessariamente mediado. Sem intervenção não se pode esperar que a educação se realize. A consciência em Hegel não é um ensimesmamento nem uma auto-suficiência. (Hegel, 2005, p. 134)

Desse modo, podemos entender que a impossibilidade do autodidatismo estaria no isolamento da consciência, o que afastaria o homem de suas relações sócio-culturais e isso o impediria de ter uma profunda consciência do seu próprio devir no devir da humanidade. Olhar para seu passado faria com que o indivíduo compreendesse a si mesmo no âmago da temporalidade. Por isso, ele tem a necessidade de aprender com alguém e com a própria história da humanidade, ou seja, com toda a história que o precedeu, para compreender, desde seu interior, o seu próprio tempo.

Parece marcar-se no pensamento de Hegel uma oposição face ao pensamento de Kant, especialmente quando o assunto é o ensino da filosofia. Diferentemente de Kant, Hegel não reconhece no homem uma predisposição ao aprendizado. Esse processo não ocorre espontaneamente, pois, para que seja possível desenvolver a abertura à aprendizagem, é fundamental a passagem do indivíduo pelo processo formativo. Desta forma, qualquer autodidatismo está fora de questão. Hegel parece propor uma tese contrária à de Kant acerca da função da filosofia e do modo como é ensinada. Sua principal discordância reside na tese de que não basta ensinar a pensar; ensinar os métodos e os conteúdos da filosofia é essencial para o processo de formação do homem.

Para que o indivíduo insira-se no movimento do espírito do tempo, melhor dizendo, no espírito objetivo do tempo, é necessário um trabalho pedagógico intenso e sistemático que compreende a recuperação consciente dos produtos do pensamento elaborados ao longo de toda a história da humanidade (poderíamos dizer história filosófica da humanidade), para que o indivíduo possa localizar-se no devir da história e, assim, integrar-se objetivamente na densidade de seu tempo, de forma a escapar da alienação, entendida como um estado de inércia em relação à sua natureza. Nesse sentido, o caminho para se evitar a alienação é o ensino dos conteúdos e dos métodos do filosofar como caminho para que o indivíduo chegue à compreensão de si mesmo. Esse caminho contribui para que o estudante compreenda intrinsecamente o devir da história da filosofia. Assim, a formação do homem, para Hegel, coincide com o sentido atribuído à noção de Bildung. Passando pelo processo de formação (Bildung), o indivíduo constroi para si mesmo uma nova natureza que se oporia a uma primeira natureza cujas características seriam o egoísmo e a imediaticidade dos fatos. 
GELAMO, Rodrigo Pelloso. The teaching philosophy and the role of philosopher-teacher in Hegel. Trans/Form/Ação, (São Paulo), v.31(2), 2008, p. 153-166.

- ABSTRACT: This paper aims to bring to light the intricacies and the particularities of Hegel's thoughts on the teaching of philosophy. Although this is not a central issue in his thought, it is possible to note his concern about the issue, more systematically in the texts he wrote during the period in which he was a professor and director of the Gymnasium in Nürember. The presentation of Hegel's thoughts on the teaching of philosophy is here divided in three parts: in the first one, the contents which Hegel thinks to be necessary for the formation of the philosophical thought are pointed; in the second one, the matter of the method and its relationship with the contents in the teaching of philosophy is presented; and finally, in the third one, it aims to understand the role that the teacher plays in this teaching.

- KEYWORDS: teaching of philosophy; Hegel; german philosophy.

\section{Referências bibliográficas}

HEGEL, F. (1809-1822) Escritos pedagógicos. México: Fondo de Cultura Econômica, 1991.

. (1809-1815) Discurso sobre educação. Lisboa: Edições Colibri, 1994.

. (1812) Ciencia de la Lógica. Trad. Augusta e Rodolfo Mondolfo. Buenos Aires: Solar S.A e Hachette, 1968.

. (1817) Enciclopédia das Ciências Filosóficas em Epítome. Trad. de Artur Morão. Lisboa: Ed. 70, 1988.

. (1807) Fenomenologia do Espírito. Trad. de Paulo Meneses e Karl-Heinz Efken. Petrópolis: Ed. Vozes, 1992.

HORN, G. B. Do ensino da filosofia à filosofia do ensino: contraposições entre Kant e Hegel. In: http://www.anped.org.br/reunioes/26/trabalhos/geraldobalduinohorn.rtf Acesso em: 10/dez/2006.

NOVELLI, Pedro Geraldo Aparecido. O ensino da filosofia segundo Hegel: contribuições para a atualidade. Trans/Form/Ação, Marília, v. 28, n. 2, 2005.

PAGNI, P. A. O ensino de filosofia nas obras de Kant, de Hegel e de Nietzsche: uma breve análise histórico-filosófica. In: Reflexão e ação. Revista do departamento de educação. UNISC: Santa Cruz do Sul. v.10, n.2, jul./dez. 2002. p. 111-135. 